Irish Math. Soc. Bulletin

Number 88, Winter 2021, 15-22

ISSN 0791-5578

\title{
David John Simms (1933-2018)
}

\author{
SIDDHARTHA SEN AND DAVID MALONE
}

David Simms was on the faculty in Trinity College Dublin from 1964 to 2003, serving as lecturer, professor and head of department. He was a dedicated lecturer who continued to teach after his retirement, and taught nearly every student who passed through the department for over fifty years. He passed away on June 24, 2018 following a long illness.

\section{EARLY Life}

David was born in 1933 in Sankeshwar, Mysore, India and proudly described himself as Indian-born. His father, J Gerald Simms, worked in the Indian civil service. His mother, Eileen (née Goold-Verschoyle), and father were both from Donegal. The family moved back-and-forth between Ireland and India several times during David's early years. David remembered speaking with children in Hindi at a young age. Later, he boarded at the English-speaking Bishop Cotton School in the Himalayas at age 8. At one stage, he contracted whooping cough, but seemed to consider his stay in the school sanatorium as something of a highlight.

In 1942, his mother began a trip back to Ireland, with her young family. As the Suez Canal was closed at the time, they traveled around the coast of Africa on the SS City of Cairo ${ }^{1}$. This ship was targetted by a German U-boat, and sunk. We will quote the 10-year old David's account of what happened.

When the torpedo hit us I was lying in the bottom bunk reading. I remember hearing a deafening boom, so I jumped out of bed but I had only gone a short way before I remembered my lifebelt. I dashed back grabbed up my lifebelt which was behind the door, took up my coat which was hooked on the cupboard handle, and tore off a blanket from the end of the bed. When I got up to the next deck I found myself squashed between a crowd of grown-ups swaying with the motion of the ship. At last I got to the top deck and went towards our lifeboat which was No.8. In the middle I stopped to put on my coat and lifebelt and then hurried to the lifeboat. I had only been there a few minutes when some sailors started shouting "Mrs. Simms!" After a time my mother came and we got into the boat with her up a ladder. ... When we got away from the ship we had to talk in whispers and the men could not smoke cigarettes because we saw the submarine, which was clear against the sky. In the distance I heard shrieks and shouts, as I was looking I saw an explosion where the

2020 Mathematics Subject Classification. 01A70.

Key words and phrases. David Simms, obituary.

Received on 20-7-2021.

DOI:10.33232/BIMS.0088.15.22.

${ }^{1}$ The story of the SS City of Cairo is fascinating and something that David had a great deal of interest in. In 1984, when a book [2] was published on the topic, David met Karl-Friedrich Merten, the captain of the U-Boat. 
boat was. I was told at that moment it was another torpedo, it looked as if the ship was blown to pieces but it had not although it sank soon after. ...

On the thirteenth day someone sighted a ship on the horizon. Everyone was very excited and went for the water in the barrels. The man in charge of the boat put some round tins, which floated, and sent up smoke, on the water, to attract the ship's attention. Soon the ship came and let down rope ladders like nets. Some officers came and helped a few who had grown weak.

After we got on the boat we were given coffee which, although it had no sugar, tasted very sweet. In the cabin I drank so much water that I did not like it for a few days after. In about seven days we arrived in Cape Town and here we are now.

The family survived this ordeal, and arrived in Cape Town. Initially, they stayed with one of David's uncles. David attended Somerset West Primary School, HottentotsHolland High School and then a Marist Brothers school in Capetown. He even played a little junior soccer for De Beers AFC, a team he recalled being weak, but the goalie did go on to play for the South African National Team.

In 1947, his father moved from the Indian Civil Service to the Home Civil Service and took a job in London. Here David attended Berkhamsted School, where Graham Green's father was his house master. The family moved to Dublin in 1949, but David stayed on as a boarder to finish his schooling.

In 1951, David entered Trinity College Dublin to study mathematics. He won an entrance scholarship, and then took the undergraduate scholarship examinations in his first year, at the encouragement of his tutor. Trinity, at this time, was much like it had been in the 1890s: lecture rooms were heated by coal fires, water came from taps in the squares and there was just one lavatory! David got involved with various activities, including the Cumann Gaelach, despite having no Irish. This seems to have made him something of a social hit, earning several mentions in the Four $\mathscr{E}_{5}$ Six column of Trinity News. He graduated in 1955 at the top of his class with a gold medal.

David wanted to go to Princeton, but he was persuaded by one of his lecturers, Arthur Allen, to do his Ph.D. in Cambridge with William Hodge. He went to Peterhouse, where Allen had been a Bye-Fellow, and was the first Robert Gardiner scholar. Hodge's previous student had been Michael Atiyah, who was visiting the Institute for Advanced Study when David first arrived in Cambridge, but he recalls Atiyah's enthusiasm bringing the place to life when he returned. David and Atiyah remained good friends for the rest of their lives. David sometimes joked that with Hodge being the greatest British mathematician of the first half of the $20^{\text {th }}$ century and Atiyah being the greatest British mathematician of the second half of the $20^{\text {th }}$ century, he was surrounded by people that he couldn't hope to live up to.

In his first year at Cambridge, Hodge told David to read a book by a young German mathematician on New Topological Methods in Algebraic Geometry. The book was by Fritz Hirzebruch, and David felt it introduced him to a new era of mathematics ${ }^{2}$. David and Hirzebruch later met at the British Mathematical Colloquium meeting in Liverpool. They also became good friends. David later spent two spells as a visiting professor in Bonn, delivering a course on Lie Groups and quantum mechanics.

David completed his thesis on The Spectral Sequence of a Pair of Coverings, and Related Cohomology Groups, and then, in 1958, he moved to the Department of Mathematics at the University of Glasgow, initially as an assistant, but was encouraged to apply for a lecturing post after 2 years. He got the lecturing post, though he contested

\footnotetext{
${ }^{2}$ David later reviewed an English translation [16].
} 
that he was never really interviewed for it. While in Glasgow, he met Anngret Erichson, later to become his wife. He also fulfilled his aim to go to Princeton, spending 1962-1963 as an instructor there while on leave of absence from Glasgow.

\section{Teaching And Service}

In 1964, David returned to Trinity to the post of Lecturer in the Department of Pure Mathematics. This was a relatively unstable time for the department, as after the long tenure of T.S. Broderick, two professors, H. Halberstam and G.A. Dirac, had passed through quickly. David had expressed an interest in returning to Dublin to Halberstam and it was between the tenure of these two professors that he returned (again, he claimed, without much of an interview). Trinity had evolved a lot in the intervening years, and there was now a physical department with staff offices.

While professor, G.A. Dirac seems to have decided that the mathematics books in the TCD library would be better housed in the mathematics department. It is unclear what the library thought of this, but regardless, Dirac organised for the books to be moved (or possibly abducted!). David took over the care of these books in 1967, and grew the library for over fifty years. In 2012, he reckoned it had over 20,000 books, which he procured, made available in the coffee room as they arrived, filed in the basement and carefully indexed (eventually using the department computer system [41]).

David's main undergraduate teaching was second year courses. In particular, for many years he taught the core senior freshman modules on algebra and analysis. Consequently, almost every mathematics student who passed through TCD was taught by David. These covered coordinate-free linear algebra, tensors, vector fields, classification of operators, calculus on manifolds, Lebesgue Integration and some complex analysis ${ }^{3}$. He carefully revised the courses every year, experimenting with different types of delivery. Students remember these modules as being an important basis for the mathematics that they did later, influencing those who went on to lecture these subjects. One student recalled them, simply, as the best lectures that they ever had.

In 1967, David delivered public lectures as part of a scheme for adults with a Leaving Cert to refresh their knowledge of mathematics. The Trinity News noted that over 30 nuns were among the 120 attending these lectures, something of a novelty in TCD at the time. The lectures were regarded as a success. Many of the attendees were teachers, possibly updating their knowledge given the significant syllabus changes introduced at the Leaving Certificate around that time.

One interesting side effect of David teaching all the students was that he knew everyone. Some students of other subjects regularly frequented the School of Maths, for access to the Maths Society or computers. These students could be stopped on the stairs so that David could quiz them and find out who they were. One tradition that he established, once settled in Dublin, was inviting all the students from his classes to dinner at his house towards the end of term. These dinners ${ }^{4}$ had something of a legendary nature among the students, who often weren't sure how to respond to such an invite. However, they seem to have left fond memories of conversations, party pieces, food and even antics on the way home. These dinners continued, with an occasional hiatus, until David officially retired. David's interest in his students extended beyond their graduation, and he was always pleased to get updates on where and what students had moved on to.

A computer committee was set up with David Simms as chairperson in 1985. While the technical details were addressed by others (including Tim Murphy as director of the

\footnotetext{
${ }^{3}$ There are course notes for these modules, as transcribed by students, available online. I hope to provide a tidied version on the arXiv. DM

${ }^{4}$ With catering organised by Anngret.
} 


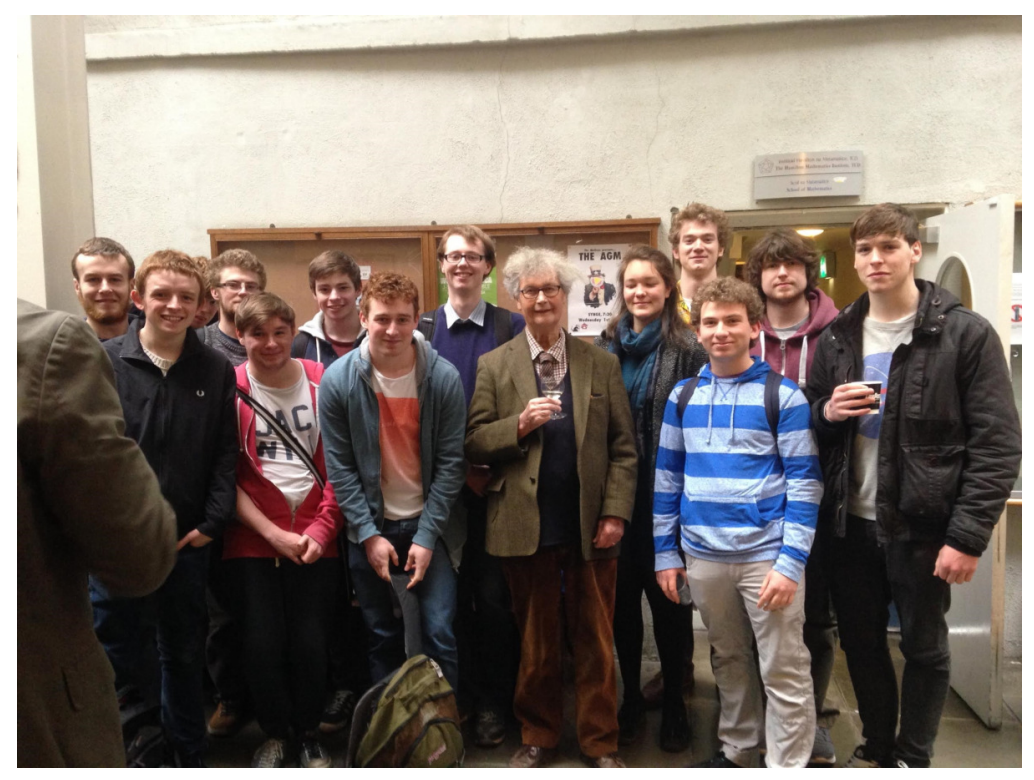

Figure 1. David Simms, with some of his class, after delivering his last lecture in 2015.

computer system [41] and Richard Timoney [3]), David oversaw funding and expenditure for the system, providing reports to the college on it and justifying its costs. David made great use of the computer system for filing away useful information. He rarely deleted any e-mails ${ }^{5}$ and had his e-mail indexed and searchable long before this became a fashionable way to access e-mail.

Over this period, David became a Fellow of the College in 1972 and an Associate Professor in 1973. He was elected as a member of the Royal Irish Academy in 1987 and was a member of the editorial board for the Mathematical Proceedings of the Royal Irish Academy.

In 1991, David became head of department. While the Department of Pure Mathematics and Department of Applied Mathematics had operated in tandem as a School of Mathematics for many years, the departments notionally had Brian Murdoch and David Spearman as independent professors. In 1988, they had merged and now David Simms was head of the School of Mathematics, covering both departments.

The college had proposed that the department was to move from House 39, at the centre of college. This move was not universally popular within the department, as there could have been reduced library space and reduced access for students to computers. There was a protest, involving a sit-in and case being brought to the Visitors. The department was eventually moved to Westland Row, near Pearse Street Station, in the summer of 1991, with allowances for more space for the department's facilities. For the first year after the move, the Hamilton Building was not yet open, and so lectures would largely take place at the far end of college in the Arts Block or Museum Building. Several additional concessions were secured from the college, including a computer room near the centre of college for 24-hour student use. The Hamilton Building opened for lectures in 1992, with two new lecture theaters available to deliver many of the department's courses.

As head of department, David introduced Theoretical Physics as a denominated entry route for the CAO in 1992. Theoretical Physics had been introduced by David

\footnotetext{
${ }^{5}$ His large mailbox was used as a template for a benchmark during the design of the filesystem index dirhash [4], which is now a part of several Unix systems.
} 
Spearman in the 1960s and 70s, but students who wanted to take this option applied to the moderatorship in science. This new entry route proved popular for applicants, and similar specialist entry routes were introduced by other universities. David Simms was horrified about the situation in which a student could get an A1 in Maths, Applied Maths, Physics and Chemistry and still not have enough points to secure entry to these courses. He managed to get the quota for the courses raised to prevent the points becoming unreasonably high ${ }^{6}$.

David continued as head of school until 1997. He became a Senior Fellow in 2002 and, although he officially retired in 2003, he continued to teach as an Emeritus Fellow until 2015.

\section{ReSEARCH}

Let us now give some highlights from David's research. David very quickly established himself as a leading researcher in the field of geometric quantization. Here his mastery of the abstract ideas of bundles and connections was used to show how the general ideas of Kostant and Sourau could be used to carry out the quantization of specific physical systems in a geometric way. The idea of geometric quantization starts from Hamilton's symplectic formulation of mechanics in which the even dimensional symplectic manifold $X$ with a closed two form $\omega$ that belongs to an integer cohomology class underpins the dynamics. On such a space $X$, a Hermitian line bundle $L$ with a $U(1)$ connection $\nabla$ and curvature given by $i \frac{\omega}{2 \pi}$ can be constructed, where $L$ is square integrable and defines a "prequantized Hilbert space $H_{0}$ ". On this space, classical observables, $f$, that are maps $f: X \rightarrow R$, become operators $O(f)$ given by $O(f)=i \hbar \nabla_{v(f)}+M_{f}$, where $v(f)$ is the Hamiltonian vector field associated with $f$. Prequantization takes the Poisson brackets of mechanics to commutators on the prequantized Hilbert space. It is a faithful map and just tells us how to reformulate classical mechanics in a novel geometric way.

To introduce quantum mechanics in this geometric setting, an additional mathematical idea is necessary. In quantum theory the full range of classical variables are no longer observables. Thus, for example, for a particle moving in one dimension, $\omega=d x \wedge d p$ where $(x, p)$ are the coordinate and momentum of the particle in $X$ and are the classical observable variables, but in quantum theory such a description is not allowed. One is only allowed to describe a state using either $x$ or $p$. This requires introducing the new idea of "polarization" to the symplectic space $X$. David carried out this procedure in a very elegant way to determine the Kepler hydrogen atom energy states and later showed that this procedure was equivalent to the way Pauli had solved the hydrogen atom problem using purely algebraic methods. The interesting point of David's analysis was that he showed that to properly construct the polarized space, half forms and thus a metaplectic structure had to be introduced to $X$.

David wrote a book with Woodhouse [40] and published several lecture notes on different aspects of Geometric Quantization, Lie Groups and Quantum Mechanics (e.g. $[30,15,35])$. These works are standard references in the field.

One can say that David had a taste for using a mix of abstract geometric ideas with group theory to solve concrete problems. His work with John Miller on the Harish Chandra c-function provides another example of this trait, and that he enjoyed explaining mathematical ideas clearly and directly to those who asked him? .

\footnotetext{
${ }^{6}$ David always had an interest in encouraging able students. Thus he helped Gerard Murphy study for A-levels [5] and met DM to discuss CAO options.

${ }^{7} \mathrm{I}$ have been a beneficiary of this. I was also told by Peter Horvathy how David spent a great deal of time explaining geometric quantization to him. SS
} 


\section{FAMILY}

It would be remiss of us not to briefly mention more about David's family, as he was dedicated to them and took pride in their achievements. After returning to Dublin, David's father decided to pursue a Ph.D. in History, became assistant to T.W. Moody and later a TCD Fellow. His wife, Anngret, who he encouraged to become an academic, became a professor in Geography in UCD. He has three sons, Brendan, Daniel and Ciaran, who all attended Trinity. The first of whom is now at Peterhouse Cambridge, the second a barrister who held an adjunct professor position in TCD, the last is now a TCD Fellow, making David the middle generation of three generations of TCD Fellows.

It is hard to cover all of David's concerns. For example, we have not touched on his interest in Finnegans Wake, his coining of Broomsday for $16^{\text {th }}$ October [10], meeting part of the Goold-Verschoyle family as part of an RTÉ documentary or his involvement with the Irish Mathematics Society. The passing of David marks the end of an era of Trinity mathematics.

\section{ACKNOWLEDGEMENTS}

We would like to thank David's family for providing the photograph and supplying details of Davis'd life. We would also like to thank David's former students who provided their reminiscences.

\section{REFERENCES}

[1] M Andrie and DJ Simms. Constants of motion and Lie group actions. Journal of Mathematical Physics, 13(3):331-336, 1972.

[2] R Barker. Goodnight, Sorry for Sinking You: The Story of the SS City of Cairo. HarperCollins, 1984.

[3] S Dineen. The mathematical legacy of Richard Timoney. In Mathematical Proceedings of the Royal Irish Academy, volume 119, pages 187-220, 2019.

[4] I Dowse and D Malone. Recent filesystem optimisations in FreeBSD. In Proceedings of the USENIX annual technical conference 2002, 2002.

[5] F Holland. Gerard J. Murphy (1948-2006). Irish Mathematical Society Bulletin, 59:9-27, 2007.

[6] J Miller and DJ Simms. A difference equation satisfied by the functions $\grave{\Gamma}_{\mu}$ of Harish-Chandra. American Journal of Mathematics, 92(2):362-368, 1970.

[7] JJH Miller and DJ Simms. Radial limits of the rational functions of Harishchandra. In Proceedings of the Royal Irish Academy. Section A: Mathematical and Physical Sciences, pages 41-47. JSTOR, 1969.

[8] JJH Miller and DJ Simms. On the coefficients of an asymptotic expansion of spherical functions on symmetric spaces. Proc. Amer. Math. Soc., 37:448-452, 1973.

[9] JJH Miller and DJ Simms. On the differential equation for spherical functions on certain symmetric spaces. Proc. Roy. Irish Acad. Sect. A, 73:19-24, 1973.

[10] F Ó Cairbre. Mathematics education and the publics interaction with the Hamilton story. Irish Mathematical Society Bulletin, 73:5-19, 2014.

[11] DJ Simms. Review: Roger Godement, topologie algébrique et théorie des faisceaux, vol. i, Actualités scientifiques et industrielles 1252, Publications de l'Institut de Mathématique de L'Université de Strasbourg XIII (Hermann, Paris), 283 pp., 3600 francs. Proceedings of the Edinburgh Mathematical Society, 11(3):189-189, 1959.

[12] DJ Simms. The spectral sequence of a covering. Proceedings of the Edinburgh Mathematical Society, 12(3):149-158, 1961.

[13] DJ Simms. Review: L. Auslander and others, flows on homogeneous spaces, Annals of Mathematics Studies 53 (Princeton University Press, 1963), vii+ 107 pp., 22s. Proceedings of the Edinburgh Mathematical Society, 14(1):83-84, 1964.

[14] DJ Simms. Spinors and rotations. Proc. Roy. Irish Acad. Sect. A, 65:69-75 (1967), 1967.

[15] DJ Simms. Lie groups and quantum mechanics. Springer, 1968.

[16] DJ Simms. Review: F. Hirzebruch, topological methods in algebraic geometry. with new appendix. translated from the 2nd German edition by RLE Schwarzenberger, with an additional section by A. Borel.(Springer-Verlag, Berlin-Heidelberg-New York, 1966), xii+ 232 pp., dm 38. Proceedings of the Edinburgh Mathematical Society, 16(1):85-85, 1968. 
[17] DJ Simms. Projective representations, symplectic manifolds and extensions of Lie algebra: lectures given at Centre de Physique Theorique CNRS, Marseille, 1969. Centre de Physique Theorique, 1969.

[18] DJ Simms. Topological aspects of the projective unitary group. Mathematical Proceedings of the Cambridge Philosophical Society, 68(1):57-60, 1970.

[19] DJ Simms. A short proof of Bargmann's criterion for the lifting of projective representations of Lie groups. Reports on Mathematical Physics, 2(4):283-287, 1971.

[20] DJ Simms. Equivalence of Bohr-Sommerfeld, Kostant-Souriau, and Pauli quantisation of the Kepler problem. Technical report, 1972.

[21] DJ Simms. Bohr-Sommerfeld orbits and quantizable symplectic manifolds. Mathematical Proceedings of the Cambridge Philosophical Society, 73(3):489-491, 1973.

[22] DJ Simms. Geometric quantisation of the harmonic oscillator with diagonalised Hamiltonian. In Proceedings of the Second International Colloquium on Group Theoretical Methods in Physics, Nijmegen, volume 168, 1973.

[23] DJ Simms. Invariance groups in classical and quantum mechanics. Zeitschrift für Naturforschung A, 28(3-4):538-540, 1973.

[24] DJ Simms. Geometric quantization of energy levels in the Kepler problem. In Symposia Mathematica, volume 14, pages 125-137. INDAM Rome, 1974.

[25] DJ Simms. The metalinear structure of the circular polarisation of the plane. In Group theoretical methods in physics (Proc. Third Internat. Colloq., Centre Phys. Theor., Marseille, 1974), Vol. 1, pages $72-76,1974$.

[26] DJ Simms. An application of polarisations and half-forms. In Non-Commutative Harmonic Analysis, pages 195-197. Springer, 1975.

[27] DJ Simms. Metalinear structures and a geometric quantisation of the harmonic oscillator. In Géométrie symplectique et physique mathématique (Colloq. Internat. CNRS, number 237, pages 163-174, 1975.

[28] DJ Simms. Symplectic structure and quantisation. In Quantum theory and the structures of time and space (Conf., Feldafing, 1974), pages 247-252. 1975.

[29] DJ Simms. Geometric quantization of symplectic manifolds. In Mathematical physics and physical mathematics. 1976.

[30] DJ Simms. A survey of the applications of geometric quantisation. In Group theoretical methods in physics (Fourth Internat. Colloq., Nijmegen, 1975), pages 111-116. Lecture Notes in Phys., Vol. 50. 1976.

[31] DJ Simms. An outline of geometric quantisation (d'après kostant). In Differential Geometrical Methods in Mathematical Physics, pages 1-10. Springer, 1977.

[32] DJ Simms. Serre duality for polarised symplectic manifolds. Reports on Mathematical Physics, 12(2):213-217, 1977.

[33] DJ Simms. On the Schrödinger equation given by geometric quantisation. In Differential geometrical methods in mathematical physics II, pages 351-356. Springer, 1978.

[34] DJ Simms. Geometric quantisation and the Feynman integral. In Feynman Path Integrals, pages 220-223. Springer, 1979.

[35] DJ Simms. Lie groups and physics. Representation theory of Lie groups (London Math. Soc. Lecture Note Series 34)(Cambridge University Press, Cambridge) p, pages 151-175, 1979.

[36] DJ Simms. Geometric quantisation for singular Lagrangians. In Differential Geometrical Methods in Mathematical Physics, pages 401-405. Springer, 1980.

[37] DJ Simms. Wave functions and transverse measures. Differential Geometric Methods in Mathematical Physics, 6:203, 1984.

[38] DJ Simms. The differential geometry of phase space and quantisation. In The Physics of Phase Space Nonlinear Dynamics and Chaos Geometric Quantization, and Wigner Function, pages 347349. Springer, 1987.

[39] DJ Simms. Prequantization. In Quantization, Coherent States, and Complex Structures, pages 103-108. Springer, 1995.

[40] DJ Simms and NMJ Woodhouse. Lectures on geometric quantization. 1976.

[41] RM Timoney. Timothy Gayleard Murphy. Irish Mathematical Society Bulletin, 82:4-10, 2018.

Siddhartha Sen is Fellow Emeritus at Trinity College Dublin and a colleague of David Simms from 1972 . 
David Malone is a Professor at the Department of Mathematics and Statistics and Hamilton Institute, Maynooth University, and a student of David Simms in the 1990s.

(Siddhartha Sen) Centre for Research in Adaptive Nanostructures and Nanodevices, Trinity College Dublin, Ireland.

(David Malone) Department of Mathematics and Statistics, Maynooth University, KilDARE, IRELAND.

E-mail address: Siddhartha.Sen@tcd.ie, David.Malone@mu.ie 